\title{
STATISTICAL ANALYSIS OF EXCLUSIVE BREASTFEEDING (EBF) AMONG MOTHERS IN AMUKOKO, NIGERIA
}

\author{
${ }^{1}$ Akingbade, A. A., "1'Ikegwu, E. M., ${ }^{2}$ Akinsola, O. J. \& ${ }^{1}$ Nwachukwu, C. F. \\ ${ }^{*}$ Department of Statistics, Yaba College of Technology, Yaba Lagos, Nigeria \\ ${ }^{2}$ Department of Community Health and Primary Care, College of Medicine University of Lagos Idi-Araba, Nigeria \\ "Corresponding Author Email: emmanuel.ikegwu@ yabatech.edu.ng Phone: +2348066940814
}

\begin{abstract}
This study assessed mothers' knowledge on, the practice of, and factors that influence exclusive breastfeeding in the initial 6 months after birth. A descriptive cross-sectional research design and purposive sampling technique were used to select 323 mothers that attended immunization at Community Health Project Amukoko and who had at least 1 child and a well-structured self-administered questionnaire was used to collect data from them. Data collected were analyzed using frequency distribution, Chi-square test, t-test and Analysis of Variance (ANOVA) were used to test significant differences in the knowledge of EBF and demographic characteristics with the aid of Statistical Package for Social Sciences (SPSS). The results show that the mean age of the mothers is 29.47 (18 - 47 years). The rate of exclusive breastfeeding was found to be $72.1 \%$ and the knowledge of mothers on exclusive breastfeeding was very good (81.81\%). The mode of delivery, introduction of prelacteal feed and introduction of water before breastfeeding have significant related to the practice of exclusive breastfeeding $(\mathrm{p}<0.05)$. The study concluded that most of the mothers had good knowledge on exclusive breastfeeding, exclusive breastfeeding rate at six months, mode of delivery, offering of prelacteal feed and introducing of water before breastfeeding is significantly associated with exclusive breastfeeding. The study recommended healthier talks and support from health care workers on breastfeeding for mothers and the use of expressed breast milk promoted among mothers.
\end{abstract}

Keywords: Chi Square Test, Cross - Sectional Research, Exclusive Breastfeeding, Expressed Milk, Pre-Lacteal Feed

LICENSE: This work by Open Journals Nigeria is licensed and published under the Creative Commons Attribution License 4.0 International License, which permits unrestricted use, distribution, and reproduction in any medium, provided this article is duly cited.

COPYRIGHT: The Author(s) completely retain the copyright of this published article.

OPEN ACCESS: The Author(s) approves that this article remains permanently online in the open access (OA) model.

QA: This Article is published in line with "COPE (Committee on Publication Ethics) and PIE (Publication Integrity \& Ethics)". 


\section{INTRODUCTION}

Colostrum is the first breast milk given to a baby by the mother or a wet nurse which provides all nutritional requirements of an infant birth. It continues to supply majority of a baby's nutritional needs for up to eighteen months (WHO, 2018b). It contains antibodies which provide immunity against microorganisms entering the body (Palmeira \& Carnoeiro-Sampaio, 2016) and critical for sustaining a new born infant's health and well-being. The colostrum (first breast milk) is pure, nutritious and rich in antibodies that shield newborns from illnesses (Nyanga, et al., 2012). The colostrum is the first immunization a child receives, laced with immunoglobulin that protects the newborn, creates a mild laxative effect, expels meconium and helps check the buildup of bilirubin (Elyas, et al., 2017). Breastfeeding aids proper mandible, dental and speech development (Okogba, 2017), enhances mothers' well-being, child - spacing, shrinks ovarian and breast cancer risks, boosts household and national resources, secures feeding and promotes environmental safety (WHO, 2018a).

Exclusive breastfeeding implies giving a baby no other food, solid or liquid (even water), except breast milk (though medicine, vitamins and mineral drops are permitted). It aids quick recovery during illness and reduces mortality in infants resulting from illnesses (WHO, 2018b). Studies have shown that Nigeria loses over $\$ 21$ billion annually and over 103,742 children annually to poor breastfeeding (Obinna, 2017). The National Nutrition and Health Survey in 2014 shows that $25 \%$ of infants 0 - 6 months are exclusively breastfed (UNICEF, 2016; NPC, 2014).

This study assessed the proportion of women that engage in 'exclusive breastfeeding' in Ajeromi - Ifelodun LGA, Nigeria; mothers' knowledge of and the factors that influence breastfeeding exclusively. Studies have shown that children breastfed perform better on mental and motor development and in academic tests than those who were not, and have higher IQs (UNICEF, 2016). Exclusive breastfeeding reduces the incidence and/or severity of bacterial such as meningitis, diarrhea, urinary tract infection, asthma and other health conditions (Kramer \& Kakuma, 2012; Godfrey \& Lawrence, 2010). Breastfeeding provides a natural contraception by holding back a nursing mother's menses as her baby is breastfed day and night within the first six months (Hossain, et al., 2018; Pirincci, Tasdemir, \& Oguzoncul, 2016; Elyas, et al., 2017). Studies have suggested that breastfeeding exclusively in the first half year delay the menstrual cycle reappearance, reduce exposure to maternal health risk associated with brief birth - interval (UNICEF, 2010) and returns mother's uterus to pre-pregnancy state (Brand, Kothari, \& Stark, 2011; Sickkids, 2009).

Breastfeeding exclusively in the first half year ensures the provision of certain biological and psychological needs of the baby and therefore increases the probability of survival during the critical stage of development. Numerous literatures show that breastfeeding education during gestation period (antenatal), is a low-technology health campaign provided at low costs in most locales (Lumbiganon, et al., 2012; Kronborg, Maimburg, \& Vaeth, 2012). Implementing education intervention during breastfeeding session and during pregnancy is beneficial in building confidence (Jamei, Ostovar, \& Javadzade, 2017). Continuing exclusive breastfeeding is positively associated with worth of guidance and care physicians and healthcare providers give concerning the decision about breastfeeding (Textor, Tiedge, \& Yawn, 2013).

Research suggests that poor knowledge of EBF is closely linked with negative attitude and low rate of the practice of breastfeeding wholly (Nwachukwu \& Nwachukwu, 2007; Ella, 2016). Early skin - to - skin contact between mother and child increases breastfeeding practice at one month and at least for four months (Moore, et al., 2012) and 
is significantly associated with breastfeeding initiated early (Singh, et al., 2017). By no means should mothers be separated from their infants' post - birth, unless for an inevitable medical reason. Researchers have shown that the longer mothers practice early skin - to - skin exchange with the baby within the first 180 minutes, the likelier she would exclusively breastfeed (Karimi, et al., 2019; Saco, et al., 2019; Bramson, et al., 2010). In a cross - sectional study in South Sudan, Warille, Onyango, \& Osano (2017) showed that $63.2 \%$ of mothers breastfed exclusively in the first 180 days, skin-to-skin post birth (70\%) and initiated breastfeeding in the 60 minutes of delivery (76.8\%). Rooming in, was reported as a practice that supports exclusive breastfeeding. However, McRae (2019) and Ng, Ho, and Lee (2019) noted that rooming - in does not significantly influence mothers' disposition to breastfeed exclusively. Avoidance of prelacteal feed has been shown to influence EBF practices.

Literature has affirmed that breastfeeding knowledge is one of the prevailing factors associated with breastfeeding exclusively. In their study on determinants of exclusive breastfeeding, Tiwari, Mahajan, and Lahariya (2009) found that only $3.8 \%$ of mothers knew that exclusive breastfeeding should be practiced up to half year and $7.8 \%$ actually did exclusive breastfeeding. Similarly, Afrose, et al. (2012) in Dhaka city, found that the overall knowledge of breastfeeding was $88 \%$ among the study subject; most are acquainted with merits of exclusive breastfeeding (89\%) and breastfed (100\%). Also, Dhakal, Lee and Nam (2017) show that $49.2 \%$ of mothers exclusively breastfed their babies and of the key indicators for this is knowledge about breastfeeding. Another study done at Ile-Ife, Osun State, Mbada, et al. (2013) found that $71.3 \%$ of the respondent had good knowledge on breastfeeding and $76 \%$ knew it stimulates mother-baby bond, a good contraceptive method (48\%) and decreases diarrhea (46\%).

According to Montgomery (2017), exclusive breastfeeding sounds great theoretically but impracticable for many moms. Socio - demographic factors found associated to exclusive breastfeeding include mode of delivery. It has been reported that women who had normal delivery are more likely to breastfeed than those who delivered through caesarian (Saco, et al., 2019). In a descriptive expository study in Nepal, Adhikari (2014) found that high level of practice regarding breastfeeding exclusively was seen more among mothers with normal delivery than those with caesarian delivery ( $65 \%$ compared to $49 \%$ ).

Similarly, Ahluwalia, Li, and Morrow (2012) noted that mothers who had induced labour or caesarian delivery were unlikely to start and sustain breastfeeding compared to mothers who had vaginal delivery. Unemployed mothers who are 2 times more likely to breastfeeding at six months than fulltime working mothers (Ryan, Zhou, \& Arensberg, 2006). Nyanga, et al. (2012) studying factors that influence knowledge and practice of exclusive breastfeeding found that $72 \%$ of employed women are less likely to breastfeed exclusively. Probably, women whose spouses are the major bread winners for the family are doubly more probable to solely breastfeed their infant compared to mothers who are main income providers. Similarly, in a study at Cross River, southern Nigeria on the determinants of exclusive breastfeeding, revealed that job condition/ nature was a contribute to mother's inability to breastfeed solely (Ella, 2016). While in Kwango District, DR Congo, it was found that marital status, literacy level and delivery place are pointers of wholesome breastfeeding (Dhakal, Lee \& Nam, 2017). Khatun, et al. (2018) and Chinofunga and Matiashe (2013) found that traditional beliefs accounted for low cause of impediment to exclusive breastfeeding. Also, in a study undertaken by Thomas (2016), mothers giving water to infants added to breast milk is seen. Some mother's 
belief that colostrum is harmful and that fresh milk is produced from the third day after delivery (Koura, 2019). Also, some mother's belief that breastfeeding is stressful and time consuming (Thomas, 2016). Many mothers are of the opinion that newborns should be given water after birth (Motee \& Jeewon, 2014; WHO, 2014). Other myths about breastfeeding are; Colostrum should be discarded, white milk should precede suckling a baby, giving rice water to sick infants, breast milk is insufficient and other foods and milk needed, breast milk too thin and it promotes allergies, traditional teas \& medicine as supplements, mothers avoiding certain foods or liquids during breastfeeding, ill or pregnant mother not breastfeed, breastfeeding mother abstain from sex because the milk will go bad (Koura, 2019; Eram, 2017; UNICEF, 2010). National Nutrition and Health survey 2014 noted that $25.2 \%$ of infants aged 0-5 months were breastfed exclusively, while $70.6 \%$ are predominantly breastfeed. The study also shows that the percentage of exclusively breastfed children aged $0-5$ months in the six geo-political zone were; North-Central $32.1 \%$, Northeast $22.3 \%$, Northwest $10.3 \%$, Southeast $18.1 \%$, South-south $30.8 \%$ and Southwest $39.8 \%$ (NPC, 2014).

\section{REVIEW OF LITERATURE}

The theory of planned behavior envisages thoughtful behaviour which can be premeditated and intentional (Record, et al., 2018). As an extension of the Theory of Reasoned Action (TRA) which advocates that behaviour is determined by intents, attitudes (behavioural philosophies), and subjective customs (others dispositional views about a behaviour).

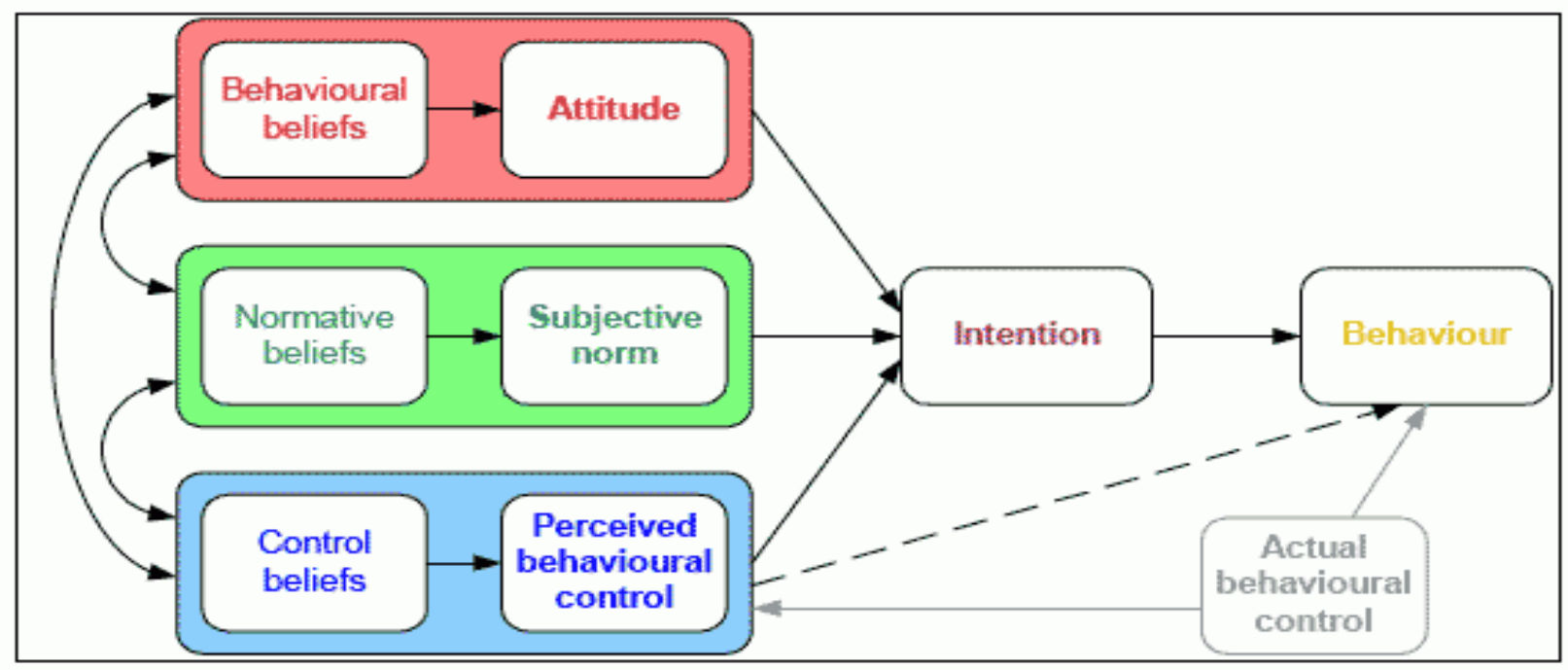

Figure 1: Theory of planned behavior

Source: https://www.cleverism.com

The theory of planned behaviour (TPB), postulated by Ajzen (1991) was an offshoot of the 'theory of reasoned actions' and opined those philosophies about one's behavioural capabilities and intents predict their behaviour. Intentions are subject to attitudes, norm prevalent and perceptions that control behaviour. The overall behaviour is assessed as attitude, while pressure from society to act out the behaviour entails the perceived norm. Perceptions on behavioural control is people's level of belief in their capacity to behave and have control over their actions (Ismail, Muda, \& 
Bakar, 2015). Therefore, attitude, subjective norms, and behavioural control predicts significantly breastfeeding intentions, which strongly predicts actual breastfeeding (Guo \& Huang, 2016).

Mothers who perceived breastfeeding as difficult are less likely to do same and usually encourage formula usage among postpartum women (Thomas, 2016). Mother's health following child birth, the father's exclusion, people's views, adverse reaction of others, and itchy feelings or discomfort controls breastfeeding difficult feelings (Giles, $e t$ al., 2007).

Breastfeeding enhances the interaction between mother and child and help the child derive the benefits of its mother's milk provided directly from the breast to the child, and offers unique experience to them each time (Primo $\&$ Marcos, 2017). Milk production offers a use or lose it process and according to Bonyata (2018), the more often and effectively an infant is nursed, the more milk the mother will make. Human breast milk contains hundreds to thousands of distinct bioactive molecules that protect against infection and inflammation, contribute to immune maturation, organ development and healthy microbial colonization with molecules such as colostrum, fat and protein and "early

initiation of breastfeeding has a higher tendency to enable the child survive pneumonia because there are certain protective factors and chemicals in the breast milk that strengthens the child response to the disease" (Akor, 2016).

Studies have shown that children breastfed do better on test of cognitive and motor development as well as academic outcomes than children who are not breastfed, and infants who are breastfed tends to have higher IQ scores (UNICEF, 2010). Exclusive breastfeeding is shown to lessen the incidence or severity of bacterial such as meningitis, diarrhea, urinary tract infection, asthma and added health conditions (Kramer \& Kakuma, 2012; Godfrey \& Lawrence, 2010). Breastfeeding also provide a natural contraception if the mother's menses have not returned, the baby is breastfeeding day and night, and the baby is less than six months old (Hossain, et al., 2018; Elyas, et al., 2017; Pirincci, Tasdemir, \& Oguzoncul, 2016). Studies have suggested that breastfeeding in the first six months may delay the return of menstrual period, and reduce the exposure to maternal health risk associated with short birth interval (UNICEF, 2010) and helps the mother's uterus to return to its pre-pregnancy state (Brand, Kothari, \& Stark, 2011; Sickkids, 2009)

\section{KNOWLEDGE AND PRACTICES OF EXCLUSIVE BREASTFEEDING}

Exclusive breastfeeding in the first half year of a baby's life ensures the provision of certain biological and psychological needs and therefore increases the probability of survival during the critical stage of development. Many studies have revealed that breastfeeding education during gestation period (Antenatal), is a key low-technology health promotion tool provided at low costs in most settings (Lumbiganon, et al, 2012; Kronborg, Maimburg, \& Vaeth, 2012). Implementing education intervention during breastfeeding session and during pregnancy period is beneficial in creating a affirmative attitude and empowering mothers to achieve controlling belief (Jamei, Ostovar \& Javadzade, 2017). The continuation of exclusive breastfeeding is positively associated with the worth of advice and support that physicians and health care providers give concerning the decision-making process in breastfeeding (Textor, et al, 2013).

Research suggests that moms with poor awareness of EBF, display negative attitude about it which accounts for the low compliance with breastfeeding exclusively (Nwachukwu \& Nwachukwu, 2007; Ella, 2016). During the 
early post-partum period, mothers need a consistence and sustained information, including enough support. In a bid to develop and maintain personal breastfeeding goals, health care professional should conduct exclusive breastfeeding promoting activities within and across sites, so as to achieve the targeted goal of healthy breastfeeding (Thomas, 2016).

\section{FACTORS ACCOUNTING FOR EXCLUSIVE BREASTFEEDING}

It has been shown that early skin to skin contact increases breastfeeding practice at 1month and at least for 4 months (Moore et al., 2012), it is significantly linked with early initiation of breastfeeding (Singh, et al., 2017). By no means should mothers be separated from infant after birth, unless for an inevitable medical reason. Researches have shown that longer practice of early skin to skin exchange with the baby within 180 minutes, would more likely result to exclusively breastfeed (Karimi, Sadeghi, Maleki-Saghooni, \& Khadivzadeh, 2019; Saco, Coca, Marcacine, Abuchaim, \& Abrao, 2019; Bramson et. al., 2010). Early initiations of breastfeeding within the 60 minutes of birth have been reported to facilitate exclusive breastfeeding.

In a cross - sectional study done in South Sudan, Warille, et.al. (2017) found that $63.2 \%$ of mothers practice exclusive breastfeeding for the first six months, $70 \%$ had skin-to-skin contact immediately after birth and $76.8 \%$ of mothers actually initiated breastfeeding in the first hour of delivery. Antenatal visits to hospitals/ health care units educate mothers on the significance and benefits of breastfeeding, and influences the decision to breastfed and boosts mothers' confidence in breastfeeding. Piro \& Ahmed (2020) and Tariku, et al. (2017) posits that mothers who attended antenatal classes are more likely to breastfeeding than those who did not attend the classes. studies have revealed that infants whose mothers did not attend prenatal breastfeeding class were five times more likely to receive infant formula supplement in the hospital than the infants whose mothers attended (Habtewold, Sharew, \& Alemu, 2019; Tariku, et al., 2017). Rooming in, has been reported as a practice that supports exclusive breastfeeding.

However, McRae (2019) and Ng, Ho, \& Lee (2019) noted that rooming - in does not significantly influence mothers' attitude towards exclusive breastfeeding. Avoidance of prelacteal feed influence EBF practices. According to the stage nine of effective breastfeeding, prelacteal feed escalates the risk of contamination in infant, and if it's been received by bottle, it's most likely to inhibit suckling. (WHO, 1998). El-Houfey (2017) reported that babies who received one or more prelacteal feed were unlikely to be fully breastfed at 6weeks. Support from peers, family and relative has been proven to have influence on exclusive breastfeeding. A study on the effect of peer counselors on exclusive breastfeeding observance showed that the occurrence of exclusive breastfeeding within 180 days was $66.7 \%$ in the intervention group and $36.6 \%$ in control group and that greater number of women in the intervention group, administered colostrum and initiated early breastfeeding (Attahiru \& Awosan, 2019).

Literature has affirmed that breastfeeding knowledge is a prevailing factor connected with exclusive breastfeeding. In their study on elements of exclusive breastfeeding, Tiwari et.al., (2009) found that only 3.8\% of mothers knew that exclusive breastfeeding should be done up to 6 months and $7.8 \%$ actually practiced 'exclusive

breastfeeding'. Similarly, Afrose et. al., (2012) in Dhaka city, found that the overall level of knowledge regarding breastfeeding was $88 \%$ among the study subject, majority of the respondent have a good knowledge of advantages of exclusive breastfeeding (89\%) and breastfeeding (100\%). Also, Dhakal et.al, (2017) shows that only $49.2 \%$ of mothers 
are exclusively breastfeeding their babies and of the key indicators for this is knowledge about breastfeeding. Another study done at Ile-Ife, Osun State, Mbada et.al. (2013) found that $71.3 \%$ of participants had good knowledge on breastfeeding. In that study, $76 \%$ knew that breastfeeding stimulates mother-baby bond, $48 \%$ knew it's a good contraceptive method, while $46 \%$ knew it decreases diarrhea.

It has been reported that mothers who delivered normally are likely to breastfeed than those who delivered through caesarian (Saco, Coca, Marcacine, Abuchaim, \& Abrao, 2019). Ahluwalia, Li \& Morrow (2012) noted that mothers who had induced labour or caesarian delivery were less likely to initiate and continue breastfeeding compared to mothers who had spontaneous vaginal delivery. It was reported that unemployed mothers were more than twice as likely to breastfeeding at six months compared to mothers who work fulltime. (Ryan, et.al. 2006). Nyanga, et.al. (2012) studying factors that influence knowledge and practice of exclusive breastfeeding found that $72 \%$ of employed women are less likely to exclusive breastfeed.

Probably, women whose spouse are the main source of income for the family are twice more likely to exclusively breastfed their infant compared to the group where mothers are the main source of income. Similarly, in a study done at Cross River, southern part Nigeria on the factors affecting exclusive breastfeeding practice, it was revealed that job condition/nature of job was a major factor responsible for mother's inability to practice exclusive breastfeeding (Ella, 2016). While in Kwango District, DR Congo, it was found that marital status, place of delivery and literacy are the indicators to for exclusive breastfeeding. (Dhakal et.al. 2017). In a study done at Enugu, it was shown that a higher maternal educational level apparently favours better exclusive breastfeeding performance. (Uchendu, Ikefuna \& Emodi, 2009). Various misconceptions by mothers have also been reported to adversely influence exclusive breastfeeding practice among mothers. Some of these are; insufficient milk production. A selfreported factor of breastfeeding was the perception of mothers that they did not have enough milk (Li, et al.,2008), and belief that sperm could get into the milk was statistically significant for age, religion, ethnic group, education, profession and number of children (Obilade, 2015). Montgomery (2017) stated that she could not continue exclusive breastfeeding due to the fact that she could not produce enough milk for her baby. In a study of assessment of hindrances to exclusive breastfeeding among mothers, Khatun, et al. (2018) and Chinofunga \& Matiashe (2013) found that traditional beliefs accounted for low cause of impediment to exclusive breastfeeding.

Also, in a study conducted by Thomas (2016), the practice of a mother giving water to an infant in addition to breast milk is common. Some mother's belief that colostrum is harmful and that fresh milk is produced from the third day after delivery (Koura, 2019). Also, some mother's belief that breastfeeding is stressful and time consuming. (Thomas, 2016). Many mothers believe that water should be given to the new born just after birth (Motee \& Jeewon, 2014; WHO, 2014). Other myths about breastfeeding are; discard Colostrum, give sick infant rice water, babies need foods and milk, breast milk give some children allergies, give traditional teas \& medicine, mothers restrained from certain foods or liquids pregnant mother not breastfeed, breastfeeding mother abstain from sex (Koura, 2019; Eram, 2017; UNICEF, 2010).

Universally, the breastfeeding rates has decline over the past four decades. The percentage of infant exclusively breastfed below 180 days in 2000 - 2007 stood at 38\% worldwide; West/Central Africa (23\%), Eastern/Southern Africa (39\%), East Asia (44\%). Added to the United State, only $79.2 \%$ of Women initiated 
breastfeeding, 49.4\% were still breastfeeding at 6 months, and 26.7\% continued breastfeeding to twelve months (CDC, 2014; UNICEF, 2008). Supplementing breast milk with water, other fluids, or foods starts at an early age in Nigeria. In 2013 only $17 \%$ of children below 180 days are exclusively breastfed which was an improvement from 13\% in 2008 (NPC, 2014). More than half of the children received water added to breast milk in the first 90 days of life.

Contrary to the recommendation of exclusive breastfeeding, $47 \%$ of children under age 6 months were given plain water, $5 \%$ received other milk, and $23 \%$ were fed complementary foods in addition to breast milk. $9 \%$ of children age 0-1 month, $16 \%$ of children age 2-3 months and 38\% of children age 4-5 months are given complementary foods. (NPC, 2014). According to the National Nutrition and Health survey 2014, 25.2\% of children age 0-5 months were exclusively breastfed, while $70.6 \%$ are predominantly breastfeed. From the study, it was shown that the percentage of exclusive breastfeeding of children age 0-5 months in the six geo-political zone were; North-central $32.1 \%$, Northeast $22.3 \%$, Northwest $10.3 \%$, Southeast $18.1 \%$, South-south $30.8 \%$ and Southwest $39.8 \%$ (NPC, 2014).

\section{MATERIALS AND METHODS}

This study was carried out at Community Health Project Amukoko in Ajeromi - Ifelodun Local Government Area, Lagos State, Nigeria among mothers with at least one child whose age are between 6 months and 5 years. The target population of this study were mothers with at least one child between the ages of 6 months to 5 years who attended the health centre for immunization and other health issues at the Community Health Project Amukoko. Ethical approval to carry out the research was sought and obtained from Health Research Ethics Committee of the Lagos University Teaching Hospital (LUTH), approval was also gotten from the coordinator of the hospital and informed consent was gotten orally from the mothers before administering the questionnaire. A descriptive cross-sectional survey design which elicited the opinion of the mothers was adopted for the study while the purposive sampling technique was used in selecting all consecutive mothers who met the inclusion criteria during the period of the study with 323 mothers as the sample size. A well-structured questionnaire validated by experts in Statistics from Yaba College of Technology, Yaba Lagos and Medicine from Lagos University Teaching Hospital, Idi -Araba Lagos ascertained the reliability using the test - retest method which was adopted as the instrument employed in the data collection. The data collected were analyzed using frequency distributions. Chi-square cross - tabulation was used on socio-demographic characteristics and factors, t-test and Analysis of Variance (Anova) to ascertain knowledge of EBF across demographic factors. The data were analyzed with the aid of SPSS 25.

\section{CHI SQUARE TEST STATISTIC}

The test statistic for the Chi-square test of Independence is denoted by $\chi^{2}$, and is computed as

$$
\chi^{2}=\sum_{i=1}^{n} \sum_{j=1}^{m} \frac{\left(O_{i j}-e_{i j}\right)^{2}}{e_{i j}}
$$

Where $O_{i j}=$ is the observed value of the $i^{\text {th }}$ row in the $j^{\text {th }}$ column and

$e_{i j}=$ is the expected value of the $i^{\text {th }}$ row in the $j^{\text {th }}$ column 
A major challenge in data collection was the researcher's inability to speak Yoruba language and some mothers who could not understand Pidgin English. However, these challenges were annulled with the help of interpreters.

\section{ETHICAL CONSIDERATIONS}

Ethical approval to carry out the research was sought from the Health Research Ethics Committee LUTH. Approval was also gotten from the coordinator of the hospital. Informed consent was gotten orally from the respondents before answering the questionnaire. Information obtained from the respondents were handled in a confidential manner so as to protect their personal information,

\section{RESULTS AND DISCUSSIONS}

The demographics of the mothers show that the majority of the mothers were married (95.3\%), $43.3 \%$ of the respondents are Yoruba, $47.4 \%$ are Igbo, $0.9 \%$ are Hausa while $8.4 \%$ are from other tribes. Based on religion, $64.4 \%$ were Christians while $35.6 \%$ were Muslim. Also, $68.7 \%$ of the mothers had secondary education as highest academic study, $21.1 \%$ had tertiary education, $9.6 \%$ had only primary education while only $0.6 \%$ had no formal education. $60.4 \%$ of the mothers are self-employed, $13.9 \%$ had formal employment, $10.2 \%$ were full-time housewives, $22 \%$ were either students or apprentices while $1.5 \%$ are neither of all. Majority of the mothers had normal delivery (91.3\%) while $8.7 \%$ had caesarian section and $12.7 \%$ of the mothers delivered their babies at home, $8 \%$ delivered at the Primary HealthCare Centres, $68.7 \%$ delivered at the hospital while 10.5\% delivered their babies through other places like the traditional ways (like traditional birth attendants).

The mothers' practices reveal that $96.3 \%$ of them attended Ante-natal clinic during pregnancy, $95.3 \%$ of the mothers planned to breastfeed their babies after delivery and $59.1 \%$ of them initiated breastfeeding in the first hour of delivery. Also, only $40.1 \%$ of the mothers had skin-to-skin contact with their baby immediately after birth. $95.6 \%$ of the mothers stayed in the same room with their babies, only $11.6 \%$ of the mothers gave their babies prelacteal feed before breastfeeding, $27.5 \%$ of them introduced water to their babies before breastfeeding, and almost 3 of every 4 mothers $(72.1 \%)$ breastfeed their babies exclusively.

In addition, only $22.7 \%$ of the mothers have expressed their breast milk for one reason or the other, $91.8 \%$ of the mothers received support from their family members in regards to breastfeeding. Lastly, $90.5 \%$ of employed mothers received maternity leave, with a mean duration of maternity leave of 3 months while only $62.2 \%$ agreed the leave period was adequate for them. Some of the reasons for not breastfeeding exclusively for at least six months include work resumption (18.2\%), not feeling like extending to six months (15.2\%), perception of insufficient breast milk $(9.1 \%)$, practice is stressful $(6.1 \%)$ while other reasons not explicitly stated (51.5\%). 


\section{Duration of exclusive breastfeeding}

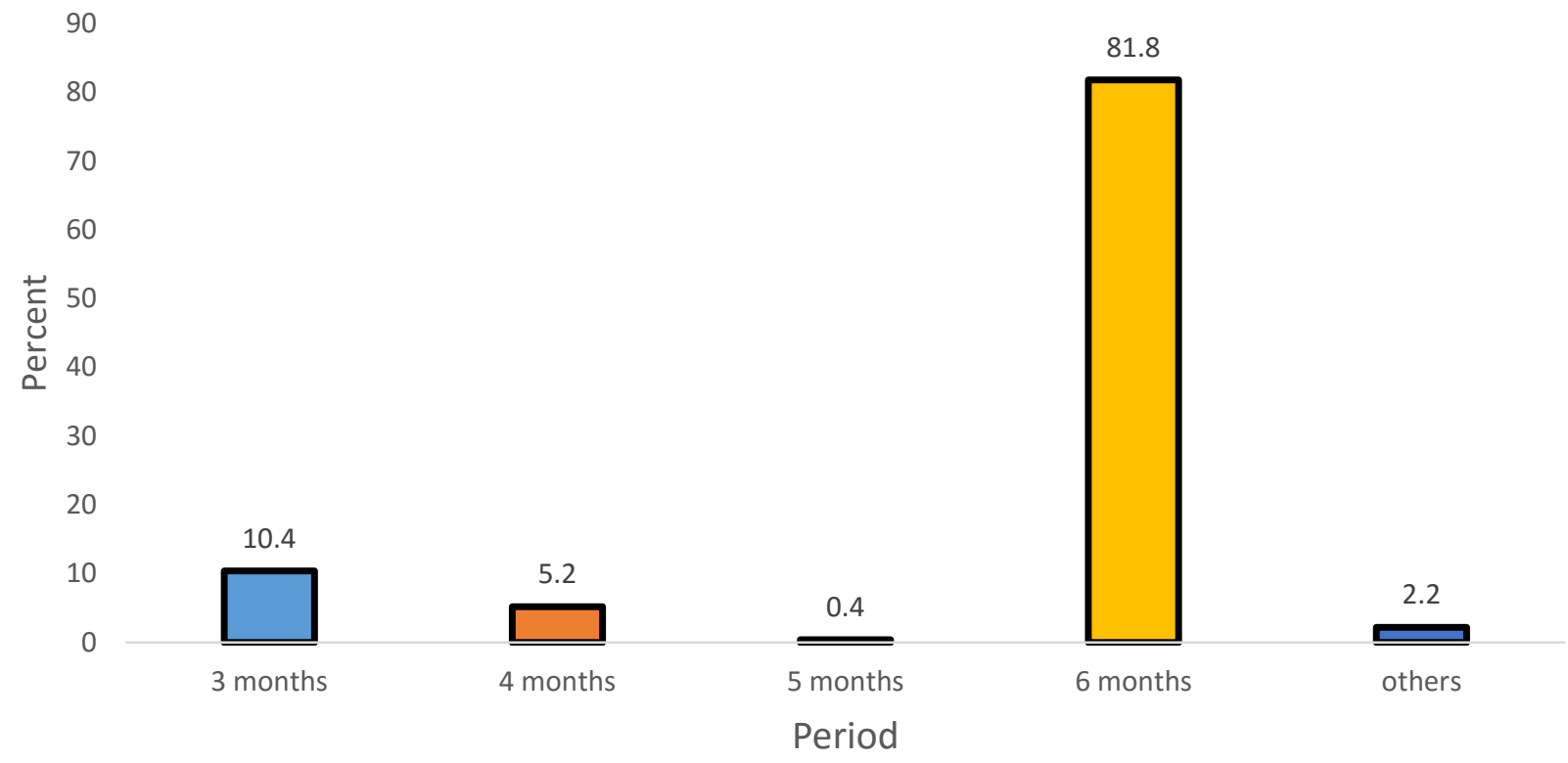

Figure 1: Duration of exclusive breastfeeding

Among those that did exclusive breastfeeding, more than 4 in every $5(81.8 \%)$ mothers breastfeed exclusively for six months, $10.4 \%$ did exclusive for three months, $5.2 \%$ did for 4 months, $0.4 \%$ did for 5 months, while $2.2 \%$ did exclusive for other durations (see fig. 2).

Table 1: Knowledge about exclusive breastfeeding

\begin{tabular}{llllll}
\hline Statements on knowledge of EBF & SA (\%) & $\mathbf{A}(\%)$ & $\mathbf{U}(\%)$ & $\mathbf{D}(\%)$ & SD (\%) \\
\hline Exclusive breastfeeding is to give baby breast milk only & $265(82)$ & $32(9.9)$ & $13(4)$ & $7(2.2)$ & $25(7.1)$ \\
Breastfeeding should be initiated within the first hour of & 206 & 49 & 18 & 14 & 35 \\
delivery & $(63.8)$ & $(15.2)$ & $(5.6)$ & $(4.3)$ & $(10.9)$ \\
Colostrum is the first milk produce, cream colour and & 247 & 27 & 35 & 5 & 9 \\
nutritious for baby & $(76.5)$ & $(8.4)$ & $(10.8)$ & $(1.5)$ & $(2.8)$ \\
Colostrum should be given to baby & 265 & 32 & 13 & 1 & 12 \\
& $(82)$ & $(9.9)$ & $(4.0)$ & $(0.3)$ & $(3.7)$ \\
Breastfeeding is beneficial to both mother and baby & 240 & 43 & 8 & 14 & 18 \\
& $(74.3)$ & $(13.3)$ & $(2.5)$ & $(4.3)$ & $(5.6)$ \\
Breastfeeding should be done on demand & 275 & 28 & 1 & 8 & 11 \\
& $(85.1)$ & $(8.7)$ & $(0.3)$ & $(2.5)$ & $(3.4)$ \\
Baby should be given water after six months & 256 & 30 & 4 & 2 & 30 \\
& $(79.3)$ & $(9.3)$ & $(1.2)$ & $(0.6)$ & $(9.3)$ \\
A mother should express her milk and keep for baby when & 72 & 42 & 58 & 16 & 135 \\
she goes to work/school & $(22.2)$ & $(13)$ & $(18)$ & $(5)$ & $(41.8)$ \\
\hline
\end{tabular}

The table 1 shows that majority of the mothers (91.9\%) knows the definition of exclusive breastfeeding, 79\% knew that breastfeeding should be initiated within the first hour of delivery, $84.9 \%$ knew what colostrum is and $91.9 \%$ agreed that it should be given to baby. Also, $87.6 \%$ of the mothers believe that breastfeeding is beneficial to both mother and baby, $93.8 \%$ agreed that breastfeeding should be done on demand, $88.6 \%$ agreed that water should be 
given to baby after six months, while only few mothers (35.3\%) agreed that a mother should express her milk and keep for baby when she goes out.

Furthermore, majority of the mothers $(80.1 \%)$ knew when complementary food should be introduced to the baby, one-fourth of mothers knew when a mother should stop breastfeeding $(25.2 \%)$ while $79.7 \%$ knew the recommended duration of exclusive breastfeeding (6 months; see fig. 3 ).

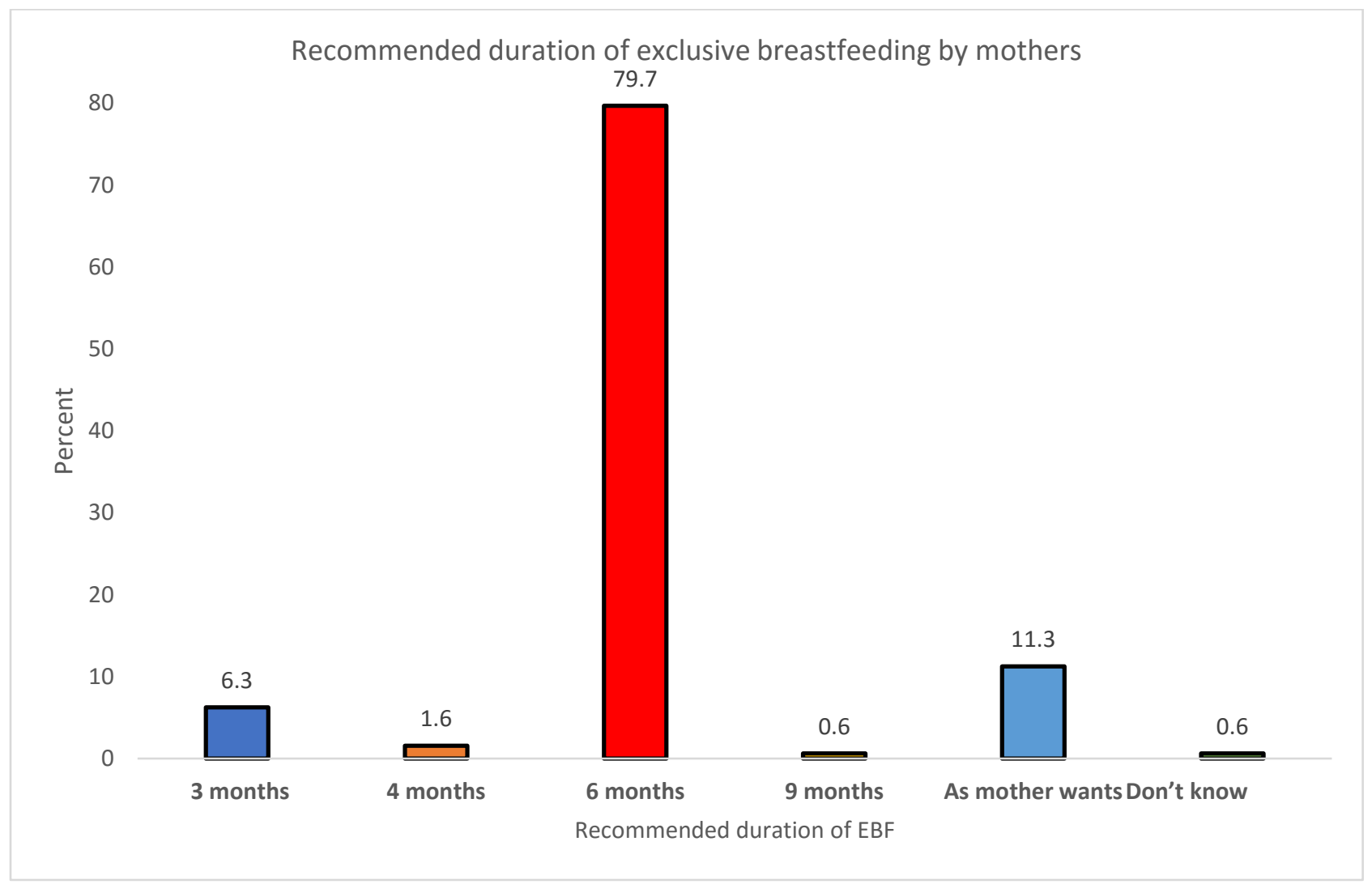

Figure 3: Bar chart of recommended duration of exclusive breastfeeding by mothers

Table 2 shows those factors that associated with exclusive breast-feeding (EBF) of babies by their mothers. While marital status, level of education, attendance of ante - natal during pregnancy, pre-plan to breastfeed, initiating breastfeeding 1 hour after delivery, having skin - to - skin contact with babies, and rooming - in were not significantly associated with exclusive breastfeeding ( $\mathrm{p}>0.05$ ), mothers' occupation, mode of delivery, offering prelateal feeding and introduction of water to babies after delivery were found to be significantly associated with EBF ( $p<0.05)$. It revealed that mothers that had caesarean section and those that offered prelateal feeding to baby after delivery were each $60 \%$ less likely to practice EBF, those that introduced water to the baby after delivery were $70 \%$ less likely to practice EBF. Lastly, mothers that attended ante - natal care were about 3 times more likely to practice EBF and those that pre-planned to breastfeed their babies were two and half times more likely to practice EBF. 
Table 2: Chi-square analysis on factors affecting exclusive breastfeeding among mothers

\begin{tabular}{|c|c|c|c|c|c|c|}
\hline \multirow[t]{2}{*}{ Variables } & \multirow[t]{2}{*}{ Categories } & \multicolumn{2}{|c|}{$\begin{array}{l}\text { Exclusively } \\
\text { breastfeed }\end{array}$} & \multirow[t]{2}{*}{$\begin{array}{l}\text { OR } \\
(95 \% \mathrm{CI})\end{array}$} & \multirow[t]{2}{*}{$\begin{array}{l}\text { Chi } \\
\text { square }\end{array}$} & \multirow[t]{2}{*}{$-\mathbf{p}$} \\
\hline & & $\begin{array}{l}\text { Yes } \\
\mathrm{N}(\%)\end{array}$ & & & & \\
\hline \multirow[t]{3}{*}{ Marital status } & Not married & 10 & 71.4 & & & \\
\hline & Married & 222 & 72.3 & \multirow[t]{2}{*}{-} & \multirow{2}{*}{0.388} & \multirow[t]{2}{*}{1.000} \\
\hline & Separated & 1 & 100 & & & \\
\hline \multirow[t]{4}{*}{ Level of education } & None & 1 & 50 & & & \\
\hline & Primary & 24 & 77.4 & & \multirow{3}{*}{2.651} & \multirow{3}{*}{0.369} \\
\hline & Secondary & 155 & 69.8 & - & & \\
\hline & Tertiary & 53 & 77.9 & & & \\
\hline \multirow[t]{5}{*}{ Occupation } & None & 5 & 100 & & \multirow{5}{*}{10.341} & \multirow{5}{*}{$0.035^{*}$} \\
\hline & Student/ apprentice & 35 & 77.8 & & & \\
\hline & House wife & 17 & 51.5 & - & & \\
\hline & Self-employed & 145 & 74.4 & & & \\
\hline & Employed & 31 & 68.9 & & & \\
\hline \multirow[t]{2}{*}{ Attended ante-natal } & No & 7 & 58.3 & 2.765 & \multirow{2}{*}{1.148} & \multirow{2}{*}{0.328} \\
\hline & Yes & 224 & 72.5 & $(0.941-8.127)$ & & \\
\hline \multirow[t]{2}{*}{ Planned to breastfeed } & No & 9 & 60 & 1.791 & \multirow{2}{*}{1.183} & \multirow{2}{*}{0.374} \\
\hline & Yes & 223 & 72.9 & $(0.619-5.187)$ & & \\
\hline \multirow[t]{2}{*}{ Mode of delivery } & Normal & 15 & 53.6 & 0.404 & \multirow{2}{*}{5.353} & \multirow{2}{*}{$0.027 *$} \\
\hline & Caesarean Section & 217 & 74.1 & $(0.184-0.888)$ & & \\
\hline \multirow[t]{2}{*}{ Initiate breastfeeding } & No & 87 & 66.4 & 1.572 & \multirow{2}{*}{3.274} & \multirow{2}{*}{0.078} \\
\hline & Yes & 143 & 75.7 & $(0.961-2.571)$ & & \\
\hline \multirow[t]{2}{*}{ Skin to skin contact } & No & 134 & 71.3 & 1.090 & \multirow{2}{*}{0.113} & \multirow{2}{*}{0.798} \\
\hline & Yes & 92 & 73 & $(0.658-1.806)$ & & \\
\hline Rooming- in & No & 7 & 50 & 2.765 & 3.682 & 0.068 \\
\hline & Yes & 224 & 73.4 & $(0.941-8.127)$ & 3.082 & 0.068 \\
\hline Offer prelacteal feed & No & 211 & 74.6 & 0.401 & 6.852 & $0.012 *$ \\
\hline Introduced water & $\begin{array}{l}\text { Yes } \\
\text { No }\end{array}$ & $\begin{array}{l}20 \\
184\end{array}$ & $\begin{array}{l}54.1 \\
79.3\end{array}$ & $\begin{array}{l}(0.199 \\
0.299\end{array}$ & & \\
\hline & Yes & 47 & 53.4 & $(0.177-0.506)$ & 21.319 & $0.000^{*}$ \\
\hline
\end{tabular}

Table 3: T-test of knowledge of exclusive breastfeeding (EBF) by factors

\begin{tabular}{|c|c|c|c|c|c|c|c|}
\hline Factors & Categories & $\mathbf{N}$ & Mean & Std dev. & $\mathbf{T}$ & $\mathbf{P}$ & Remarks \\
\hline Did exclusively & No & 90 & 77.22 & 17.03 & \multirow{2}{*}{-3.657} & \multirow{2}{*}{$<0.001^{*}$} & \multirow[b]{2}{*}{ Sig. } \\
\hline breastfeed & Yes & 233 & 83.59 & 12.68 & & & \\
\hline Attended antenatal & No & 12 & 68.00 & 17.22 & \multirow{2}{*}{-3.470} & \multirow{2}{*}{$<0.001^{*}$} & \multirow{2}{*}{ Sig. } \\
\hline clinic & Yes & 309 & 82.35 & 14.00 & & & \\
\hline Religion & Christian & 208 & 84.15 & 12.81 & \multirow{2}{*}{4.051} & \multirow{2}{*}{$<0.001 *$} & \multirow{2}{*}{ Sig. } \\
\hline & Muslim & 115 & 77.58 & 15.82 & & & \\
\hline Mode of delivery & Normal delivery & 293 & 81.44 & 14.37 & \multirow{2}{*}{-1.776} & \multirow{2}{*}{0.077} & \multirow{2}{*}{ Not sig. } \\
\hline & Caesarian section & 28 & 86.45 & 13.01 & & & \\
\hline Planned & No & 15 & 73.75 & 14.46 & \multirow{2}{*}{-2.290} & \multirow{2}{*}{$0.023^{*}$} & \multirow{2}{*}{ Sig. } \\
\hline breastfeed & Yes & 306 & 82.32 & 14.14 & & & \\
\hline
\end{tabular}

*Significant at $5 \%$ level of significance

Table 3 tests the difference in knowledge of EBF between different categories of the factors under consideration. It shows that those that those who practiced EBF has significantly better knowledge of the concept than those that do 
not practice it $(\mathrm{p}<0.05)$. Also, those that attend antenatal clinic has significantly more knowledge on exclusive breastfeeding than those who did not attend $(\mathrm{p}<0.05)$. In addition, it shows that there is a significant difference in the knowledge of EBF among Christians and Muslims ( $\mathrm{p}$ 0.05). Furthermore, it shows that there is no significant difference in the knowledge of EBF between mothers who had normal delivery and those that had caesarean section $(\mathrm{p}<0.05)$. Lastly, it revealed that mothers who planned to breastfeed when they are pregnant has significantly better knowledge of EBF than those who did not pre-plan to breastfeed $(\mathrm{p}<0.05)$.

Table 4: Analysis of Variance test of the knowledge of EBF by the factors

\begin{tabular}{|c|c|c|c|c|c|c|c|c|}
\hline Factors & Categories & $\mathrm{N}$ & Mean & Std. dev. & $\mathrm{df}$ & $\mathrm{F}$ & $\mathrm{P}$ & Remarks \\
\hline \multirow[t]{4}{*}{ Ethnicity } & Yoruba & 140 & 78.25 & 15.32 & \multirow{4}{*}{3,319} & \multirow{4}{*}{6.544} & \multirow{4}{*}{$<0.001^{*}$} & \multirow{4}{*}{ Sig. } \\
\hline & Igbo & 153 & 85.29 & 12.91 & & & & \\
\hline & Hausa & 3 & 87.50 & 10.83 & & & & \\
\hline & Others & 27 & 79.98 & 12.05 & & & & \\
\hline Level & None & 2 & 95.31 & 2.21 & \multirow{4}{*}{3,319} & \multirow{4}{*}{4.102} & \multirow{4}{*}{$0.007^{*}$} & \multirow{4}{*}{ Sig. } \\
\hline \multirow[t]{3}{*}{ education } & Primary & 31 & 74.90 & 16.74 & & & & \\
\hline & Secondary & 222 & 81.75 & 14.80 & & & & \\
\hline & Tertiary & 68 & 84.77 & 9.84 & & & & \\
\hline \multirow[t]{6}{*}{ Occupation } & None & 5 & 75.36 & 11.87 & & \multirow{6}{*}{0.515} & \multirow{6}{*}{0.765} & \multirow{6}{*}{ Not sig. } \\
\hline & Student & 42 & 88.33 & 15.29 & \multirow{5}{*}{5,317} & & & \\
\hline & House wife & 33 & 79.45 & 14.00 & & & & \\
\hline & Apprentice & 3 & 82.29 & 22.61 & & & & \\
\hline & Self-employed & 195 & 81.83 & 14.23 & & & & \\
\hline & Employed & 45 & 82.75 & 13.87 & & & & \\
\hline Place & Home & 41 & 81.10 & 14.52 & \multirow{4}{*}{3,319} & \multirow{4}{*}{1.253} & \multirow{4}{*}{0.291} & \multirow{4}{*}{ Not sig. } \\
\hline \multirow{3}{*}{ delivery } & Primary Health Care & 26 & 81.49 & 15.38 & & & & \\
\hline & Hospital & 222 & 82.62 & 13.82 & & & & \\
\hline & Others & 34 & 77.63 & 15.95 & & & & \\
\hline
\end{tabular}

Table 4 shows that the Hausas has the highest mean knowledge of EBF $(87.29 \%$; sd $=10.83 \%)$ while the Yoruba's has the least mean knowledge of $\operatorname{EBF}(78.25 \%$; $\mathrm{sd}=15.32 \%)$, and that there is significant difference in the knowledge of EBF by mothers among tribes ( $\mathrm{p}<0.05$ ). Also, it reveals that mothers with no formal education have the highest mean knowledge of $\mathrm{EBF}(5.31 \%$; sd $=2.21 \%)$ while mothers with only primary education have the least mean knowledge of $\operatorname{EBF}(74.90 \%$; sd=16.74) and there is significant difference in knowledge of EBF among the mothers by level of education $(\mathrm{p}<0.05)$. Lastly, there is no difference in the knowledge of EBF by the occupation of mothers and their place of delivery $(\mathrm{p}<0.05)$.

\section{DISCUSSION}

This study considered the practice, knowledge and factors that stimulate 'exclusive breastfeeding' (EBF) among mothers. Findings showed that $81.8 \%$ of the mothers absolutely breastfeed their baby for the period of 180 days, which is higher than 55.8\% in Techiman, Ghana reported by Boateng (2018) and 70\% in Ondo State reported by Olatubi (2016). The difference is attributable to the importance placed on 'exclusive' breastfeeding and high cost of living in Lagos State which makes use of any complementary milk for babies unaffordable. The theory of planned behaviour 
was positively applied to detect the wide range of behaviors as it was found that majority of the mothers (95.3\%) planned to breastfeed during gestation period but only $72.1 \%$ actually did for half year, while some gave their babies water and breast milk, because they belief that babies should be given water, as adult eats and take water. Some breastfed exclusively but below half year because of their husbands, mothers and peer groups. A mother declared that, "My husband said I should give my baby water, for how do I feel when I eat without drinking water" while another said "I gave my baby water because that is how my mother breastfed me".

These findings are consistent with other studies on the mothers' practice of giving water to infants which is not only maternal intents and attitude, but difference in the perception of the power of one's control factor (Thomas, 2016; Martin, 2017). The study also found that occupation has no significant association with exclusive breastfeeding which agrees with Warille et al., (2017) in South Sudan but disagrees with the conclusions of Ella (2016) in Cross River State and Nyanga et al., (2012) in Kenya that a significant relationship exists between them.

This study also found that $59.1 \%$ of mothers-initiated breastfeeding in the first hour of delivery, which is slightly higher than $21.1 \%$ reported by Ajibuah (2013) in Yobe, Northern Nigeria. The study found that $95.6 \%$ of the mothers stayed in the same room with their baby (rooming - in) which is higher than $79.1 \%$ reported Mbada et al., (2013) in Osun State. It was also found that those who practice rooming in are almost three time more likely to breastfeed their baby exclusively than those who do not that rooming in has no significant association with exclusive breastfeeding which agreed with other studies (McRae, 2019; Ng, Ho, \& Lee, 2019; Thomas, 2016). It was also found that there is significant association between exclusively breastfeeding and offering of prelacteal feed and that those who did offer prelacteal feed to their baby are $60 \%$ less likely to breastfeed exclusively which agreed with Amele, Demissie, Desta, \& Woldemariam (2019) and Ogundele, Ogundele, \& Adegoke (2019), that infants who receive prelacteal feed were less probable to be fully breastfeed at six weeks. Introduction of water before feeding with breast was found to have significant association with exclusive breastfeeding and that moms who introduced water before breastfeeding are $70 \%$ less likely to exclusively breastfeed their babies.

It also found that $96.3 \%$ of the mothers attended antenatal visit in pregnancy and that $72.5 \%$ of them exclusively breastfed their babies in agreement with Tender et.al. (2009) that the babies whose mothers failed prenatal classes are more likely to receive infant formula. It also found that there is no significant association between exclusive breastfeeding and the mothers' level of education which negated the findings of Uchendu, Ikefuna \& Emodi, 2009) at Enugu, Eastern Nigeria that higher maternal education level favours better exclusive breastfeeding. This could be a result of very high percentage of mothers who attended antenatal classes during pregnancy where information about the importance and benefits of breastfeeding are provided.

The study also found that marital status has no significant association with exclusive breastfeeding and the result contradicts other findings in Kenya and Kwango District of DR Congo (Dhakal et.al, 2017; Nyanga et.al., 2012). The study found that $91.8 \%$ of the mothers received support with regards to breastfeeding and this is slightly higher than $88.5 \%$ reported in South Sudan by Warille, et.al. (2017) which is attributable to the supports received from spouses and their mothers. The study found that mothers have very good knowledge $(81.81 \%, \mathrm{sd}=14.24 \%)$ of exclusive breast feeding which is slightly lower than 86\% reported by Mbada et al (2014) in Osun State and $92 \%$ by Boateng (2018) in Ghana. The study also found that $91.9 \%$ of the mothers knew the definition of exclusive 
breastfeeding, slightly higher than $78.9 \%$ reported by Warille et al (2017) in South Sudan as a result of high rate of healthy orientation by healthcare workers during antenatal and immunization. Also, it found that $78.9 \%$ of the mothers knew the recommended duration of exclusive breastfeeding almost same as 77\% reported by Olatubi (2016) found in Ondo State.

This study also found that those that practice EBF has higher knowledge of EBF than those who did not, and those who attended antenatal care than those who did not attend which supports the findings of Kronborg, Maimburg \& Vaeth, (2012) that antenatal education is a vital, low cost and low technology health promotion tool. The study also reviewed that the Hausas has more knowledge of EBF, than the other ethnic nationalities, Christians has better knowledge of EBF than Muslims, those without any formal education than those with any formal education. Also, it found that mothers who pre-planned to breastfeed has better knowledge of EBF than those who do not and that the difference is significant while mothers who delivered at the hospital has better knowledge of EBF than the others which could be a consequence of better information and orientation received from healthcare workers which agreed with other researchers (Agu \& Agu, 2011; John, 2005).

\section{CONCLUSION}

The study therefore concluded that the proportion of 'exclusive breastfeeding' (EBF) in Ajeromi - Ifelodun LGA, Lagos State is $81.8 \%$, and the elements that significantly influence the practice of EBF include occupation, mode of delivery, offer of pre-lacteal feeding and introduction of water to babies before breastfeeding. Also, understanding of exclusive breastfeeding was generally very high, and the factors that weigh - in significantly on this knowledge include ethnicity, level of education, religion, attendance to antenatal clinic, pre-plan to breastfeed during pregnancy and actual practice of EBF. In furtherance of the mothers' knowledge and exercise of exclusive breastfeeding, more aggressive health orientations (in the language mothers will understand) should be implemented. Also, all levels of governments, should help in disseminating information online, via television, radio jingles on the significance of EBF to reach all facets of society. Lastly, religious bodies in the country should imbibe the principle of indoctrinating their congregants on the necessity and priority of EBF for healthier children and society.

\section{CONFLICT OF INTEREST}

The authors declare that there is no conflict of interest as the study was fully designed, implemented and financed solely by the authors.

\section{ACKNOWLEDGEMENTS}

We acknowledge the assistance of the entire staff of Community Health Project Amukoko in Ajeromi - Ifelodun Local Government Area, Lagos State. 


\section{REFERENCES}

Adhikari, T. (2014, sep-dec). Knowledge and Practice of Mother regarding Exclusive Breastfeeding Having Infant at a Tertiary Level Hospital, Kathmandu. Journal of Nepal Paediatric Society, 34(3), 200-206. Retrieved from http://search.ebscohost.com

Afrose, L., Banu, B., Ahmed, K., \& Khanom, K. (2012). Factors associated with knowledge about breastfeeding among female garment workers in Dhaka city. WHO South-East Asia Journal of Public Health, 1(3), 249255. doi:10.4103/2224-3151.207021

Agu, M., \& Agu, U. (2011). Knowledge and practice of exclusive breastfeeding among mothers in a rural population in South eastern Nigeria. Tropical Journal of MedicalResearch, 15(2).

Ahluwalia, I., Li, R., \& Morrow, B. (2012, August 28). Breastfeeding Practices: Does Method of Delivery Matter? Maternal and Child Health Journal, 16(2), 231-237. doi:http://doi.org/10.1007/s10995-012-1093-9

Ajibuah, B. (2013). Appraisal of Nursing Mothers' Knowledge and Practice of Exclusive Breastfeeding in Yobe State, Nigeria. Journal of Biology, Agriculture and Healthcare, 3(20).

Ajzen, I. (1991). The Theory of Planned Behaviour. Organisational Behaviour and Human Decision Processes, 50, $179-211$.

Akor, O. (2016). what exclusive breastfeeding does for baby, family, nation. DAILY TRUST.

Amele, E. A., Demissie, B. W., Desta, K. W., \& Woldemariam, E. B. (2019). Prelacteal feeding practice and its associated factors among mothers of children age less than 24 months old in Southern Ethiopia. Italian Journal of Pediatrics, 45(15), 1 - 8. doi:10.1186/s13052-019-0604-3

Attahiru, A., \& Awosan, K. J. (2019). Utilisation of maternity services and breastfeeding practices of working mothers in Sokoto, Nigeria. International Archives of Medicine and Medical Sciences, 1(1), 16 - 22.

Boateng, M. F. (2018, May). Knowledge, Attitude and Practice of Exclusive breastfeeding among Mothers in Techiman, Ghana. Master's thesis, University of Eastern Finland, Public Health. Retrieved Dec 10, 2018, from http://www.urn_nbn_fi_ue...0180869

Bonyata, K. (2018). (K. m. breastfeeding, Ed.) Retrieved from https://kellymom.com>hot-topics>milk

Bramson, L., Lee, J., Moore, E., Montgomery, S., Neish, C., Bahjri, K., \& Melcher, C. (2010, May). Effect of early skin-to-skin mother-infant contact during the first 3 hours following birth on exclusive breastfeeding during the maternity hospital stay. J Hum Lact., 26(2), 130-137. doi:10.1177/0890334409355779.Epub 2010 Jan 28

Brand, E., Kothari, C., \& Stark, M. A. (2011). Factors Related to Breastfeeding Discontinuation Between Hospital Discharge and 2 Weeks Postpartum. The Journal of Perinatal Education, 20(1), 36 - 44.

CDC. (2014). Breastfeeding report card. Department of Health \& Human Services. United States: Centre for Diseases Control. Retrieved 06 30, 2018, from http://www.cdc.gov/breastfeeding/pdf/2014breastfeedingreportcard

Chinofunga, D., \& Matiashe, I. (2013). Assessment of hindrances to Exclusive Breastfeeding among mothers in Vungu. Semantic Scholar.

Dhakal, S., Lee, T., \& Nam, E. (2017, April 25). Exclusive Breastfeeding Practice and Its Association among Mothers of under 5 Children in Kwango District, DR Congo. International Journal of Enviromental Research and Public Health, 14(455). doi:10.3390/ijerph14050455

El-Houfey, A., Saad, K., Abbas, A., Mahmoud, S., \& Wadani, M. (2017, November 11). Factors that influence Exclusive Breastfeeding: A literature Review. International Journal Of Nursing Didactics, 7(11), 24-31. doi:http://dx.doi.org/10.15520/ijnd.2017.vol7.iss11.264.24-31 
Ella, R. (2016). Factors Affecting Exclusive Breastfeeding Practice in Rural Communities of Cross River State, Nigeria. International Journal of Humanities Social Sciences and Education (IJHSSE), 3(4), 101-110. doi:http://dx.doi.org/10.20431/2349-0381.0304012

Elyas, L., Mekasha, A., Admasie, A., \& Assefa, E. (2017, December). Exclusive breastfeeding practice and associated factors among Mothers attending Private Pediatric and Child Clinics, Addis Ababa, Ethiopia: A Crosssectional Study. (F. Porta, Ed.) International Journal of Pediatrics, 2017. doi:10.1155/2017/8546192

Eram, U. (2017). A Review Article: Myths, Beliefs, and Amlpractices relating to Breastfeeding and Complementary feeding practices. International Journal of Pharmaceutical Science Invention, 6(1), 14 - 16.

Giles, M., Conner, S., Carol, M., Mallett, J., Stewart-Knox, \& Wright, M. (2007). Measuring young people's attitudes to breastfeeding using the Theory of Planned Behavior. Journal of Public Health, 29(1), 48-52. doi:https://doi.org/10.1093/pubmed/fd1076

Godfrey, J., \& Lawrence, R. A. (2010, September). Toward Optimal Feeding:The Maternal Benefits of Breastfeeding. Journal of Women's Health19(9):, 1597-1602. doi:10.1089/jwh.2010.2290.

Guo, J., \& Huang, R. (2016). Efficacy of the theory of planned behaviour in predicting breastfeeding: Meta-anaysis and structural equation modeling. Applied Nursing Research, $29, \quad 37 \quad-\quad 42$. doi:http://doi.org/10.1016/j.apnr.2015.03.016

Habtewold, T. D., Sharew, N. T., \& Alemu, S. M. (2019). Evidence on the effect of gender of newborn, antenatal care and postnatal care on breastfeeding practices in Ethiopia: a meta - analysis and meta - regression analysis of observational studies. BMJ Open, 9, e023956. doi:10.1136/bmjopen-2018-e023956

Hossain, M., Islam, A., Kamarul, T., \& Hossain, G. (2018). Exclusive breastfeeding practice during first six months of an infant's life in Bangladesh: a country based cross-sectional study. BMC Pediatrics, 18, 93 [online].

Ismail, T., Muda, W., \& Bakar, M. (2015). The extended theory of planned behavior in explaining exclusive breastfeeding intention and behavior among women in Kelenta, Malaysia. Nutrition Research Practice. online, 10(1), 49-55. doi:10.4162/nrp.2016.10.1.49

Jamei, F., Ostovar, A., \& Javadzade, H. (2017). Application of Exclusive Breastfeeding among Nulliparous Iranian Mothers. International Journal Pediatric, 5(3), 4457-4467. doi:10.22038/IJP.2016.20815.14

John, R. (2005, April). Knowlege, attitude and practice of employed mothers about breastfeeding. Journal of Nursing India, 96(4), 85-86.

Karimi, F. Z., Sadeghi, R., Maleki-Saghooni, N., \& Khadivzadeh, T. (2019). The effect of mother - infant skin to skin on success and duration of first breastfeeding: A systematic review and meta analysis. Taiwanese Journal of Obstetrics and Gynecology, 58(1), 1 - 9.

Khatun, H., Comins, C. A., Shah, R., Islam, M. M., Choudhury, N., \& Ahmed, T. (2018). Uncovering the barriers to exclusive breasting for mothers living in Dhaka's slums: a mixed method study. International Breastfeeding Journal, 13(44), 1 - 11. doi:10.1186/s13006-018-0186-5

Koura, H. (2019). Myths about breastfeeding. Al - Azhar Assiut Medical Journal, 17, 109 - 113.

Kramer, M. S., \& Kakuma, R. (2012, August 15). Optimal duration of exclusisive breastfeeding,. (C. p. group, Ed.) Cochrane Database of Systematic Review(8). doi:10.1002/14651858.CD003517

Kronborg, H., Maimburg, R., \& Vaeth, M. (2012, Dec). Antenatal training to improve breastfeeding: a randomized trial. journal of Midwifery, 28(6), 784-790. doi:10.1016/j.midw.2011.016 
Li, S., Fein, S., Chen, J., \& Grummer-Strawn, L. (2008, October). Why Mothers stop Breastfeeding: Mothers' Selfreported Reasons for Stopping During the First Year. Pediatrics: AAP News \& Journals Gateway, 122(2), 569-576.

Lumbiganon, P., Martis, R., Laopaiboon, M., Festin, M., Ho, J., \& Hakimi, M. (2012, september). Antenatal breastfeeding education for increasing breastfeeding duration. Cochrane Database System Rev, 12(9). doi:10.002/14651858.CD006425.pub3

Martin. (2017, October 28). Cleverism. Retrieved from http://www.cleverism.com

Mbada, C., Olowookere, A., Faronbi, J., Oyinlola-Aromolaran, F., Faremi, F., Ogundele, A., \& Augustine, O. (2013). Knowledge, attitude and techniques of breastfeeding among Nigeria mothers from a semi-urban community. BMC Research Notes, 6(552). doi.org/10.1186/1756-0500-6-552

McRae, M. J. (2019). Exclusive Breastfeeding, 24 - Hours Rooming - In, and the Importance of Women's Informed Choices. Nursing Women Health, 23(4), 309 - 315. doi:10.1016/j.nwh.2019.05.003

Montgomery, S. (2017, November 25). Actually, exclusive breastfeeding is impossible for most Moms. Retrieved 05 20, 2018, from http://www.romper.com

Moore, E., Anderson, G., Bergman, N., \& Dowswell, T. (2012). Early skin-to-skin contact for mothers and their healthy newborn infants. The Cochrane Database of systematic Reviews.(5). doi:10.1002/14651858.CD003519.pub3

Motee, A., \& Jeewon, R. (2014). Importance of Exclusive Breastfeeding and Complimentary feeding among Infants. Current Research in Nutrition and Food Science, 2(2), [online]. doi:10.12944/CRNFSJ.2.2.02

Ng, C. A., Ho, J. J., \& Lee, Z. H. (2019). The effect of rooming-in on duration of breastfeeding: A systematic review of randomised and non - randomised prospective controlled studies. Plos One, 14(4), e0215869.

NPC (2014). Nigeria Demographic And Health Survey, 2013. Abuja, Nigeria, and Rockville, Maryland, USA: National Population Commission, Nigaria and ICF International.

Nyanga, N., Musita, C., Otieno, A., \& Kaseje, D. (2012, October). Factors Influncing Knowledge and Practice of Exclusive Breastfeeding in Nyando District, Kenya. African Journal of Food, Agriculture, Nutrition and Development, 12(6).

Nwachukwu, A., \& Nwachukwu, A. (2007). Common factors responsible for less than six months period of exclusive breastfeeding women in Nigeria. Journal of International council for Health, Physical Education, Recreation, Sport ad Dance(JCHPER-SD), 43(2), 30-35.

Obilade, T. T. (2015). The Knowledge, Attitude and Practice of Exclusive Breastfeeding among mothers in two semiurban areas around a Baby Friendly Hospital Initiative (BFHI) designated hospital in Lagos State, Nigeria. International Archives of Medicine, 8(1), 1 - 13. doi:10.3823/1614

Obinna, C. (2017, July 23). You can lose that baby if you don't breastfeed him for six months. Sunday Vanguard, p. [online]. Retrieved May 12, 2020, from vanguardngr.com/2017/07/can-lose-that-baby-if-you-dontbreastfeed-him-for-six-months

Ogundele, T., Ogundele, O. A., \& Adegoke, A. I. (2019). Determinants of Prelacteal feeding practices among mothers of children age less than 24 months in Ile - Ife SouthWest Nigeria: a community cross-sectional study. Pan American Medical Journal, 34(172), 172 [online]. doi:10.11604/pamj.2019.34.172.17642

Okogba, E. (2017). Water is the greatest barrier to exclusive breastfeeding-Ada Ezeogu, UNICEF Nutritionist. Vanguard News. Retrieved from http://www.vanguardngr.com 
Olatubi, M. I., \& Olufarati, G. (2016). Knowledge and Practice of Exclusive Breastfeeding Among Mothers Attending Infant Welfare Clinicin a TertiaryHealth Institution. Journal of Health, Medicine and Nursing, 28.

Palmeira, P., \& Carnoeiro-Sampaio, M. (2016). Immunology of breast milk. Revista da Associacao Medica Brasileira, 62(6), 584 - 593. doi:10.1590/1806-9282.62.06.584

Piro, S. S., \& Ahmed, H. M. (2020). Impacts of antenatal nursing interventions on mothers' breastfeeding self efficacy: an experimental study. BMC Pregnancy and Childbirth, 20, 19 (2020) [online]. doi:10.1186/s12884-019-2701-0

Pirincci, E., Tasdemir, R., \& Oguzoncul, A. F. (2016). Knowledge of lactational amenorrhea as a contraceptive method among mothers of infants aged 0 - 6 months in a district, Eastern Turkey. International Journal of Community Medicine and Public Health, 3(6), 1363 - 1370.

Primo, C., \& Marcos, A. (2017, Nov/Dec). interactive theory of breastfeeding: creation and application of middle range theory. Rev. Bras. Enterm, 70 (.6 Brasilia), online.

Record, R. A., Harrington, N. G., Helme, D. W., \& Savage, M. W. (2018). Using the Theory of Planned Behaviour to guide Focus Group development of Messages aimed at increasing Compliance with tobacco-free policy. American Journal of Helath Promotion, 32(1), 143 - 152.

Ryan, A., Zhou, W., \& Arensberg, M. (2006). The effect of employment status on breastfeeding in the United States. Women's Health Issues, 16(5), 243-251. doi:10.1016/j.Whi.2006.08.001

Saco, M. C., Coca, K. P., Marcacine, K. O., Abuchaim, E. S., \& Abrao, A. C. (2019). Skin - to - skin contact followed by breastfeeding in the first hour of life: Associated factors and influences on exclusive breastfeeding. Texto Contexto Enferm [Internet], 28, e20180260. doi:10.1590/1980-265X-TCE-2018-0260

Sickkids. (2009, September 11). Childbirth recovery and postpartum care. Retrieved May 09, 2020, from aboutkidshealth.ca: www.aboutkidshealth.ca/Article? contentid=415\&language =English

Singh, K., Khan, S., Aguirre, L., Brodish, P., Amouzou, A., \& Moran, A. (2017, December 20). The importance of Skin-to-skincontactmfor early initiation ofbreastfeeding in Nigeria and Bangladesh. Journal of Global Health, 7(2). doi:10.7189/jogh.07.020505

Tariku, A., K., A., Gizaw, Z., Muchie, K. F., Derso, T., Abebe, S. M., . . Biks, G. A. (2017). Mother's education and ANC visit improved exclusive breastfeeding in Dabat Health and Demographic Surveillance System Site, NorthWest Ethiopia. Plos One, 12(6), e0179056. doi:10.1371/journal.pone.0179056

Textor, L., Tiedge, K., \& \& Yawn, B. (2013). Mexican and Somali Immigrant breastfeeding initiation and Counseling. Minnesota Medicine, 96(12), 46-50.

Thomas, J. (2016). Barriers to Exclusive Breastfeeding among Mothers during the first Four weeks Postpartum. Walden Dissertations and Doctoral Studies. Retrieved from http://scholarworks.waldenu.edu/dissertations

Tiwari, R., Mahajan, P., \& Lahariya, C. (2009, february 1). The detrminant of exclusive breastfeeding in urban slums: a community based study. Journal of Tropical Pediatrics, 55(1), 49-54. doi:10.1093/tropej/fmn037

Uchendu, U., Ikefuna, A., \& Emodi, I. (2009, January). Factors associated with exclusive breastfeeding among mothers seen at University of Nigeria Teaching Hospital, Enugu. South African Journal of Child Health, 3(1), 13-19.

UNICEF. (2008). The state of the world's Children 2009: Maternal and Newborn Health. UNICEF.

UNICEF. (2010). Improving Exclusive Breastfeeding Practices by using Communication for Development. UNICEF Web-based Orientation Series for Programme and Communication, 2011-12. 
UNICEF. (2016). More than 5 million Nigerian new born miss out on head start in life. Retrieved july 10, 2018, from http://www.unicef.org>media_10520

Warille, E., Onyango, F., \& Osano, B. (2017, february). Knowledge and practice of Exclusive breastfeeding among women with children Hospital, Juba, South Sudan. South Sudan Medical Journal, 10(1), 12-16.

WHO. (2018a). Breastfeeding. WHO; Nutrition. Retrieved from http://www.who.int

WHO. (2018b, March 1). Exclusive breastfeeding for optimal growth, development and health of infants. e-Library of Evidence for Nutrition Actions (eLENA). Retrieved from http://www.who.int.

WHO. (2014, July 29). Why can't we give water to a breastfeeding baby before the 6 months, even when it is hot? Retrieved May 12, 2020, from who.int: who.int/news-room/q-a-detail/Why-can-t-we-give-water-to-abreastfeeding-baby-before-the-6-months-even-when-it-is-hot

WHO. (1998). Evidence for the ten steps to successful breastfeeding. Division of Child Health and Development, 24,31,48. Retrieved 05 15, 2018 